\title{
Gambaran Luaran Fungsional Tatalaksana Pasien Neglected Fraktur Sub- trokanter Menggunakan Reversed Distal Femur Limited Contact Dynamic Compression Plate di Rumah Sakit Bhayangkara Manado
}

\author{
Lilik Rifai, ${ }^{1}$ Rangga B. V. Rawung, ${ }^{2}$ Angelica Wagiu ${ }^{2}$
}

\author{
${ }^{1}$ Program Studi Pendidikan Dokter Fakultas Kedokteran Universitas Sam Ratulangi, Manado, \\ Sulawesi Utara, Indonesia \\ ${ }^{2}$ Bagian Ilmu Bedah Fakultas Kedokteran Universitas Sam Ratulangi, Manado, Sulawesi \\ Utara, Indonesia \\ Email: lilikherawaty99@gmail.com
}

\begin{abstract}
Subtrochanter fracture is still a health problem due to the difficulty of treatment and the high incidence of non-union and malunion after treatment. Limited Contact-Dynamic Compression Plate (LC-DCP), an implant designed to be used in distal femur fractures, is reported as an alternative for the treatment of subtrochanter fractures. This study was aimed to obtain the functional outcome of neglected subtrochanter fractures using reversed distal femur LC-DCP at Bhayangkara Hospital Manado. This was a retrospectoive study using the medical record and by-phone evaluation of patients with neglected subtrochanter that were managed with the reversed distal femur LC-DCP in 2018-2019 at Bhayangkara Hospital, Manado. Patients were evaluated with the Harris Hip Score (HHS). The results showed that there were 6 patients who met the inclusion criteria and could be contacted by phone. The HHS results showed 6 patients of poor category (mean score of 25.6) at 3 months after surgery; 3 patients of poor category and 3 patients of fair category (mean score of 66.4) at 6 months after surgery; and 4 patients of good category and 2 patients of excellent category (mean score of 89.9) at 12 months after surgery. In conclusion, the functional outcomes of the patients were poor category at 3 months after surgery, poor to fair at 6 months after surgery, and good to excellent at 12 months after surgery.
\end{abstract}

Keywords: functional outcome, neglected subtrochanter fracture, reversed distal femur limited contact - dynamic compression plate, Harris hip score

\begin{abstract}
Abstrak: Fraktur subtrokanter masih merupakan masalah kesehatan karena sulitnya penanganan dan tingginya angka kejadian non-union dan malunion setelah penanganan. Limited contactdynamic compression plate (LC-DCP) yaitu implan yang dirancang untuk fraktur femur bagian distal dilaporkan dapat dijadikan alternatif untuk penanganan fraktur subtrokanter. Penelitian ini bertujuan untuk memperoleh gambaran luaran fungsional tatalaksana pasien neglected fraktur subtrokanter menggunakan reversed distal femur LC-DCP di RS Bhayangkara Manado. Jenis penelitian ialah retrospektif menggunakan data rekam medis dan evaluasi melalui telepon pada pasien dengan neglected fraktur subtrokanter yang ditatalaksana menggunakan reversed distal femur LC-DCP pada tahun 2018-2019 di RS Bhayangkara Manado. Pasien dievaluasi dengan Harris Hip Score (HHS). Hasil penelitian mendapatkan 6 pasien yang memenuhi kriteria inklusi. Hasil evaluasi HHS mendapatkan 6 pasien kategori poor (rerata skor 25,6) saat 3 bulan pasca operasi; 3 pasien kategori poor dan 3 pasien fair (rerata skor 66,4) saat 6 bulan pasca operasi dengan; dan 4 pasien kategori good dan 2 pasien dengan kategori excellent (rerata skor 89,9) saat 12 bulan pasca operasi. Simpulan penelitian ini ialah luaran fungsional pasien-pasien tersebut ialah HHS poor pada 3 bulan pasca operasi; HHS poor-fair 6 bulan pasca operasi; dan HHS good-excellent pada 12 bulan pasca operasi.
\end{abstract}

Kata kunci: luaran fungsional, neglected fraktur subtrokanter, reversed distal femur limited contact - dynamic compression plate, Harris hip score 


\section{PENDAHULUAN}

Neglected fracture adalah kasus fraktur yang tidak ditangani atau ditangani dengan tidak sesuai sehingga menyebabkan keterlambatan penanganan, kondisi memburuk, atau bahkan kecacatan. ${ }^{1}$ Studi mengenai kasus neglected fracture di Indonesia masih kurang dan belum banyak dilaporkan.

Fraktur subtrokanter adalah fraktur yang terjadi antara area trokanter minor hingga $5 \mathrm{~cm}$ ke arah distal. ${ }^{2}$ Kejadian fraktur ini mewakili $10-34 \%$ fraktur panggul. ${ }^{3}$ Beberapa studi menjelaskan bahwa kejadian fraktur subtrokanter memiliki distribusi bimodal berdasarkan usia dimana dapat terjadi pada usia muda yang biasanya pada laki-laki oleh karena high energy trauma sedangkan pada usia tua biasanya terjadi pada perempuan oleh karena low energy trauma dengan disertai adanya osteoporosis. ${ }^{4,5}$ Sampai saat ini, fraktur subtrokanter masih menjadi masalah kesehatan karena sulitnya penanganan dan tingginya angka kejadian non-union dan malunion setelah penanganan. ${ }^{6}$

Fiksasi internal merupakan pilihan utama untuk penanganan fraktur subtrokanter yang bertujuan untuk mengembalikan struktur anatomi dengan tepat sehingga memungkinkan fraktur bersatu. Terdapat dua jenis implan yang digunakan yaitu intramedullary implant dan extramedullary implant., 3 Beberapa studi menyatakan bahwa penggunaan intramedullary implant merupakan baku emas untuk penanganan fraktur subtrokanter namun tidak semua kasus bisa menggunakan jenis implan ini. Dalam hal ini extramedullary implant merupakan sebuah pilihan. ${ }^{7,8}$

Dynamic compression plate-distal femoral (DCP-DF) yaitu implan yang dirancang untuk digunakan pada fraktur femur bagian distal telah dilaporkan dapat dijadikan alternatif untuk tatalaksana fraktur femur proksimal. ${ }^{7}$ Sampai saat ini belum ada studi yang melaporkan tentang luaran fungsional pasien neglected fraktur yang ditatalaksana menggunakan DCP-DF di Manado. Berdasarkan hal tersebut maka penulis terdorong untuk mengetahui luaran fungsional tatalaksana pasien neglected fraktur subtrokanter menggunakan reversed distal femur LC-DCP di RS Bhayangkara Manado.

\section{METODE PENELITIAN}

Penelitian ini dilaksanakan di Rumah Sakit Bhayangkara Manado pada tahun 2018-2019. Jenis penelitian ini ialah deskriptif retrospektif menggunakan data rekam medis pasien dengan neglected fraktur subtrokanter yang ditatalaksana menggunakan reversed distal femur LCDCP Kriteria inklusi pada penelitian ini yaitu pasien laki-laki dan perempuan dengan neglected fraktur subrochanter yang ditatalaksana menggunakan reversed distal femur LC-DCP, berusia 17-65 tahun yang tercatat di rekam medik tahun 2018 - 2019. Pasien memiliki data rekam medis yang lengkap tentang identitas, nomor telepon pribadi, dan data yang berkaitan dengan luaran fungsional berdasarkan Harris Hip Score (HHS) yang meliputi nyeri, adanya gangguan gait, kebutuhan akan alat bantu, aktivitas sehari-hari, serta hasil pemeriksaan fisik berupa penilaian ada tidaknya deformitas dan nilai range of motion hip. Data yang diperoleh disajikan dalam bentuk tabel dan persentase.

\section{HASIL PENELITIAN}

Dalam studi ini didapatkan data sebanyak 6 pasien neglected fraktur subtrokanter yang ditatalaksana menggunakan reversed distal femur $L C-D C P$ ) di Rumah Sakit Bhayangkara pada tahun 2018- 2019 yang memenuhi kriteria inklusi dan berhasil dievaluasi melalui telepon.

Subjek penelitian ini terdiri dari 5 pasien laki-laki $(77,8 \%)$ dan 1 pasien perempuan $(22,2 \%)$. Terdapat 3 pasien kelompok usia 17-25 tahun, 1 pasien kelompok usia 26-35 tahun, 1 pasien kelompok usia 36-45 tahun, dan 1 pasien kelompok 46-55 tahun. Penyebab kejadian fraktur subtrokanter pada 6 pasien oleh karena high energy trauma.

Tabel 1 menunjukkan secara lebih rinci komponen penilaian yang terdapat dalam Harris hip score (HHS) dan dijabarkan jumlah pasien sesuai masing-masing kom- 
ponen berdasarkan waktu 3 bulan, 6 bulan, dan 12 bulan pasca operasi.

Dalam penellitian ini didapatkan saat 3 bulan pasca operasi 4 pasien mengeluhkan nyeri berat dan 2 pasien dengan nyeri sedang. Saat 6 bulan pasca operasi 6 pasien merasakan nyeri ringan, sedangkan 12 bulan pasca operasi didapatkan 6 pasien merasakan nyeri sesekali.

Penggunaan alat bantu 3 bulan setelah operasi didapatkan 3 pasien menggunakan 2 tongkat dan 3 pasien dengan $2 \mathrm{kruk} / \mathrm{tidak}$ dapat berjalan. Sedangkan 6 bulan setelah operasi didapatkan 3 pasien menggunakan 2 tongkat, 1 pasien menggunakan tongkat untuk sebagian besar waktu, dan 2 pasien menggunakan tongkat untuk jarak jauh. Saat 12 bulan setelah operasi didapatkan 4 pasien menggunakan tongkat untuk jarak jauh dan 2 pasien tanpa pengggunaan alat bantu.

Jarak berjalan yang dapat ditempuh 3 bulan pasca operasi didapatkan 3 pasien dapat berjalan dari tempat tidur ke kursi roda saja dan 3 pasien dapat berjalan hanya dalam ruangan. Kemudian 6 bulan pasca operasi didapatkan 4 pasien dapat berjalan 400-600 yard dan 2 pasien dapat berjalan 200-300 yard. Saat 12 bulan setelah operasi didapatkan jarak berjalan yang dapat ditempuh tidak terbatas pada 6 pasien.

Dalam studi ini didapatkan saat 3 bulan pasca operasi 6 pasien mengalami keluhan pincang yang berat hingga tidak bisa berjalan. Saat 6 bulan pasca operasi didapatkan 3 pasien dengan keluhan pincang sedang dan 3 pasien dengan keluhan sedikit pincang. Saat 12 bulan pasca operasi didapatkan 2 pasien tanpa keluhan pincang dan 4 pasien masih dengan sedikit kepincangan.

Berdasarkan data rekam medik didapatkan 3 bulan pasca operasi sebagian besar pasien mengalami kesulitan dalam menjalani aktivitas sehari-hari yang dinilai berdasarkan kemampuan menggunakan sepatu dan kaus kaki, kemampuan naik turun tangga, kemampuan menggunakan transportasi umum, dan kenyamanann saat duduk. Terdapat 5 pasien belum dapat menggunakan sepatu dan kaus kaki, dan 1 pasien kesulitan menggunakan sepatu dan kaus kaki. Mengenai kemampuan naik turun tangga, 3 bulan pasca operasi didapatkan 5 pasien belum mampu dan 1 pasien memerlukan bantuan untuk naik turun tangga. Tiga bulan pasca operasi terdapat 6 pasien belum mampu menggunakan transportasi umum secara mandiri. Selain itu, 4 pasien lebih nyaman duduk di kursi tinggi dan 2 pasien belum nyaman untuk duduk di kursi apapun.

Mengenai kemampuan menjalankan aktivitas sehari-hari saat 6 bulan pasca operasi didapatkan 4 pasien dengan mudah menggunakan sepatu dan kaus kaki dan 2 pasien masih kesulitan menggunakan sepatu dan kaus kaki. Mengenai kemampuan naik turun tangga didapatkan 5 pasien mampu naik turun tangga dengan memegang railing dan 1 pasien dengan bantuan lain. Mengenai kemampuan menggunakan transportasi umum 6 bulan pasca operasi didapatkan 4 pasien telah mampu dan 2 pasien belum mampu menggunakan transportasi umum secara mandiri. Untuk kenyamanan saat duduk didapatkan 4 pasien nyaman untuk duduk di kursi apapun selama 1 jam dan 2 pasien lebih nyaman duduk menggunakan kursi tinggi.

Mengenai kemampuan menjalankan aktivitas sehari-hari saat 12 bulan pasca operasi didapatkan 6 pasien dengan mudah menggunakan sepatu dan kaus kaki. Kemampuan naik turun tangga didapatkan 4 pasien mampu naik turun tangga tanpa memegang railing dan 2 pasien mampu naik turun tangga dengan memegang railing. Untuk kemampuan menggunakan transportasi umum didapatkan 6 pasien mampu menggunakan transportasi umum secara mandiri. Selain itu, kenyamanan saat duduk 12 bulan setelah operasi didapatkan 6 pasien telah nyaman duduk dikursi apapun selama 1 jam.

Dalam studi ini, pada 6 pasien tidak didapatkan deformitas pasca operasi.

Pada pengukuran derajat fleksi hip saat 3 bulan pasca operasi terdaapt 6 pasien dengan derajat fleksi $<70^{\circ}$, sedangkan saat 6 bulan pasca operasi didapatkan 2 pasien dengan derajat fleksi $>75^{\circ}, 1$ pasien $>80^{\circ}, 3$ pasien $>90^{\circ}$ kemudian saat 12 bulan pasca operasi didapatkan 2 pasien dengan derajat fleksi $>90^{\circ}$ dan 4 pasien $>110^{\circ}$.

Pada pengukuran derajat abduksi hip 
saat 3 bulan pasca operasi, didapatkan 6 pasien dengan derajat abduksi $>5^{0}$, sedangkan 6 bulan pasca operasi didapatkan 3 pasien dengan derajat abduksi $>10^{\circ}, 2$ pasien $>15,{ }^{0}$ dan 1 pasien $>20^{\circ}$, kemudian 12 bulan pasca operasi didapatkan 6 pasien dengan derajat abduksi $>20^{\circ}$.

Peada pengukuran derajat eksternal rotasi hip 3 bulan pasca operasi didapatkan 6 pasien dengan derajat eksternal rotasi $>5^{0}$, saat 6 bulan pasca operasi didapatkan 6

Tabel 1. Komponen penilaian Harris Hip Score pasien derajat eksternal rotasi $>10^{0}$, kemudian 12 bulan pasca operasi didapatkan 6 pasien dengan derajat eksternal rotasi $>15^{0}$.

Pada pengukuran derajat adduksi hip saat 3 bulan pasca operasi didapatkan 6 pasien derajat adduksi $>5^{0}$, sedangkan 6 bulan pasca operasi didapatkan 6 pasien derajat adduksi $>10^{\circ}$, kemudian 12 bulan pasca operasi didapatkan 6 pasien dengan derajat adduksi $>15^{\circ}$.

\section{Komponen penilaian}

\section{Nyeri}

a. Tidak ada

b. Sedikit/sesekali

c. Nyeri ringan

d. Nyeri sedang

f. Nyeri berat

e. Hanya bisa terbaring di tempat tidur

\section{Penggunaan alat bantu}

a. Tidak perlu

b. Tongkat untuk jarak jauh

c. Tongkat untuk sebagian besar waktu

d. 1 kruk

e. 2 tongkat

f. 2 kruk/tidak dapat berjalan

\section{Jarak berjalan yang dapat ditempuh}
a. Tidak terbatas
b. 400 - 600 yard
c. 200 - 300 yard
d. Hanya dalam ruangan
e. Dari tempat tidur ke kursi saja

\section{Ada tidaknya keluhan pincang}
a. Tidak ada
b. Sedikit
c. Sedang
d. Berat hingga tidak bisa berjalan

\section{Jumlah pasien}

6 bulan

12 bulan

3 bulan

Kemampuan menggunakan sepatu dan kaus kaki
a. Dengan mudah
b. Sulit
c. Tidak bisa

\section{Kemampuan naik turun tangga}

a. Normal tanpa memegang railing (pegangan tangga)

b. Normal dengan memegang railing

0
0
0
2
4
0

\section{0}

0

0

6

0

0

0

\section{0}

\section{2}

\section{1}

\section{0}

3

0

\section{0}

\section{4}

2

$$
0
$$$$
0
$$

\section{0}

$$
3
$$$$
3
$$$$
0
$$

0
6
0
0
0
0
0

2
4
0
0
0
0

0

0

0

2

4

0

$\begin{array}{lll}6 & 0 & 0\end{array}$

$\begin{array}{lll}0 & 4 & 6\end{array}$

$\begin{array}{lll}1 & 2 & 0\end{array}$

$\begin{array}{lll}5 & 0 & 0\end{array}$

$\begin{array}{lll}0 & 0 & 4\end{array}$

$0 \quad 5 \quad 2$
6 
c. Bisa dengan bantuan lain

d. Tidak mampu naik turun tangga

Kemampuan menggunakan transportasi umum
a. Mampu
b. Tidak mampu

$\begin{array}{lll}0 & 4 & 6 \\ 6 & 2 & 0\end{array}$

$\begin{array}{lll}1 & 1 & 0 \\ 5 & 0 & 0\end{array}$

\section{Kenyamanan saat duduk}
a. Kursi apapun selama 1 jam

$\begin{array}{lll}0 & 4 & 6 \\ 4 & 2 & 0 \\ 2 & 0 & 0\end{array}$
c. Tidak nyaman untuk duduk di kursi apapun

\section{Deformitas}
a. Ada
b. Tidak ada

$\begin{array}{lll}0 & 0 & 0 \\ 6 & 6 & 6\end{array}$

\section{Fleksi hip}
a. $<70$
b. $>70$
c. $>75$
d. $>80$
e. $>90$
f. $>100$
g. $>110$

$\begin{array}{lll}6 & 0 & 0 \\ 0 & 0 & 0 \\ 0 & 2 & 0 \\ 0 & 1 & 0 \\ 0 & 3 & 2 \\ 0 & 0 & 0 \\ 0 & 0 & 4\end{array}$

\section{Abduksi hip}
a. $>5$
b. $>10$
c. $>15$
d. $>20$

$\begin{array}{lll}6 & 0 & 0 \\ 0 & 3 & 0 \\ 0 & 2 & 0 \\ 0 & 1 & 6\end{array}$

\section{Eksternal rotasi hip}
a. $>5$
b. $>10$
6
0
c. $>15$

$\begin{array}{ll}0 & 0 \\ 6 & 0 \\ 0 & 6\end{array}$

Adduksi hip
a. $>5$
b. $>10$
6
$0 \quad 0$
c. $>15$

$\begin{array}{lll}0 & 6 & 0\end{array}$
$0 \quad 0 \quad 6$

Tabel 2 menunjukkan hasil akhir kategori HHS dari 6 pasien yang dapat terhubung dan dievaluasi melalui telepon.

Tabel 2. Evaluasi kategori HHS pada pasien

\begin{tabular}{ccccc}
\hline $\begin{array}{c}\text { Waktu } \\
\text { pasca } \\
\text { operasi }\end{array}$ & \multicolumn{4}{c}{ Hasil Harris Hip Score } \\
\hline 3 bulan & 6 & Fair & Good & Excellent \\
6 bulan & 3 & 3 & 0 & 0 \\
12 bulan & 0 & 0 & 4 & 2 \\
\hline
\end{tabular}

Pada penelitian ini didapatkan hasil evaluasi HHS dari 6 pasien, yaitu: saat 3 bulan pasca operasi keenam pasien tergolong poor; saat 6 bulan pasca operasi: 3 pasien dengan HHS tergolong poor dan 3 pasien tergolong fair; dan saat 12 bulan pasca operasi: 4 pasien tergolong good dan 2 pasien tergolong excellent.

\section{BAHASAN}

Hasil penelitian terhadap pasien neglected fraktur subtrokanter yang ditata- 
laksana menggunakan reversed distal femur limited contact - dynamic compression plate (reversed distal femur LC-DCP) di Rumah Sakit Bhayangkara tahun 2018-2019 mendapatkan data 6 pasien yang memenuhi kriteria inklusi dan dapat dilakukan evaluasi melalui telepon.

Telah dipaparkan sebelumnya bahwa kejadian fraktur subtrokanter memiliki distribusi bimodal berdasarkan usia yaitu dapat terjadi pada usia muda yang biasanya pada laki-laki oleh karena high energy trauma sedangkan pada usia tua biasanya terjadi pada perempuan oleh karena low energy trauma dengan disertai adanya osteoporosis. ${ }^{4,5}$ High energy trauma yang sering terjadi pada usia muda salah satunya ialah akibat kecelakaan lalu lintas dengan jumlah kejadiaan di Indonesia terbanyak pada usia 16-30 tahun. ${ }^{2,9}$ Berdasarkan penelitian yang dilakukan oleh Zai et al ${ }^{10} \mathrm{di}$ RSUP Prof. Dr. R. D. Kandou Manado didapatkan bahwa distribusi pasien yang mengalami trauma akibat kecelakaan lalu lintas menurut jenis kelamin terbanyak pada laki-laki yang dikaitkan dengan jumlah lakilaki yang aktif mengemudi lebih banyak dibandingkan perempuan, serta pola perilaku dengan risiko tinggi saat mengemudi. Dalam penelitian ini distribusi jumlah pasien menurut golongan usia didapatkan jumlah terbanyak pada golongan usia 17-25 tahun sebanyak 3 pasien (50\%) dan berdasarkan jenis kelamin didapatkan 5 pasien laki-laki $(83,3 \%)$ dan 1 pasien perempuan $(16,7 \%)$ sedangkan distribusi pasien berdasarkan penyebab fraktur terbanyak akibat high energy trauma yaitu sebanyak 6 pasien (100\%).

Pada beberapa studi telah dijelaskan bahwa penggunaan intramedullary implant merupakan baku emas untuk penanganan fraktur subtrokanter. ${ }^{11}$ Penelitian yang dilakukan oleh Xie et $\mathrm{a}^{12}$ dan Singh et al ${ }^{13}$ melaporkan bahwa penggunaan intramedullary implant lebih baik daripada extramedullary implant dalam hal waktu operasi lebih pendek, kehilangan darah intraoperatif lebih sedikit, panjang insisi lebih pendek, lama rawat inap dan hasil fungsional lebih baik. Namun, dalam situasi tertentu intramedullary implant tidak dapat digunakan seperti pada keadaan dimana garis fraktur mencapai fossa piriformis (Russel Taylor II), pasien dengan tulang pendek dan medula yang sempit, deformitas parah pada tulang femur, serta pada beberapa tempat dengan fasilitas kesehatan yang kurang memadai. ${ }^{7,14}$ Dalam hal ini, penggunaan extramedullary implant dapat menjadi alternatif pilihan.

Hasil penelitian ini memperlihatkan bahwa pada penggunaan reversed distal femur reversed distal femur $L C-D C P$ saat 3 bulan pasca operasi sebagian besar pasien memiliki nilai cukup rendah dalam aspek fungsional yang dinilai berdasarkan keluhan ada tidaknya nyeri yang dirasakan, penggunaan alat bantu, jarak berjalan yang dapat ditempuh, ada tidaknya keluhan pincang, kemampuan memakai sepatu dan kaus kaki, kemampuan naik turun tangga, kemampuan menggunakan transportasi umum, dan kenyamanan saat duduk. Sejalan dengan hal tersebut, salah satu studi menyatakan bahwa pengukuran dengan tujuan melihat perkembangan fungsi dan keberhasilan terapi biasanya dapat dilihat 6 bulan pasca operasi yaitu secara statistik dan anatomis pada periode waktu tersebut mayoritas pasien telah mulai menunjukan perkembangan dan kestabilan implan. ${ }^{15}$ Saat 6 bulan pasca operasi didapatkan peningkatan nilai dalam aspek fungsional dibandingkan 3 bulan sebelumnya dan sebagian besar pasien telah mampu melakukan aktivitas sehari-hari seperti menggunakan sepatu dan kaus kaki, naik turun tangga, menggunakan transportasi umum secara mandiri, dan nyaman untuk duduk di kursi apapun. Saat 12 bulan pasca operasi didapatkan peningkatan bermakna serta nilai yang cukup memuaskan dalam aspek fungsional dimana keluhan nyeri yang dirasakan pasien mulai berkurang bahkan tidak ada nyeri, beberapa pasien tidak perlu alat bantu untuk berjalan, jarak berjalan yang dapat ditempuh tidak terbatas, sedikit keluhan pincang pada beberapa pasien, mampu menggunakan sepatu dan kaus kaki dengan mudah, mampu naik turun tangga, mampu menggunakan transportasi umum secara mandiri, dan 
nyaman untuk duduk di kursi apapun.

Pada penelitian ini didapatkan sebagian besar pasien mengeluhkan rasa tidak nyaman terutama saat berdiri maupun jongkok dalam waktu yang lama. Hal ini dapat dikaitkan dengan letak dari plate yaitu dibawah dari otot-otot pada regio femoris. ${ }^{16}$

Berdasarkan studi biomekanika oleh Tazawa et $\mathrm{al}^{8}$ dan Wang et $\mathrm{al}^{17}$ didapatkan bahwa intramedullary nail memberikan fiksasi yang lebih stabil daripada extramedullary implant. $^{8}$ Secara biomekanika intramedullary nails dan pelat didasari dengan konsep yang berbeda. Pelat didasarkan pada konsep implant penahan beban, sedangkan intramedullary nail didasarkan pada konsep berbagi beban. Oleh karena itu intramedullary nail dapat menahan gaya tekan yang lebih besar daripada pelat. $^{8}$ Selain itu, salah satu studi menjelaskan bahwa reversed distal femur LC-DCP menggunakan sistem screw-plate dengan kemampuan anti-shearing dari plate ini lebih buruk dibandingkan sistem intramedullary nail sehingga pasien yang menggunakan reversed distal femur LC-DCP tidak diizinkan untuk menahan beban pada periode awal pasca operasi. ${ }^{16}$

Penelitian oleh Han et $\mathrm{al}^{18}$ membandingkan penggunaan proximal femoral nails (PFN) dan reverse-DFLCP pada fraktur intertrokanterik dan melaporkan bahwa pasien dengan PFN lebih nyaman dalam early mobilization dibandingkan pasien dengan reverse-DFLCP namun untuk luaran fungsional setelah 12 bulan didapatkan kedua kelompok menunjukkan hasil yang tidak jauh berbeda.

Pada penelitian yang dilakukan oleh Lin et $\mathrm{al}^{19}$ didapatkan bahwa luaran yang dihasilkan penggunaan reverse less invasive stabilization system-distal femur (LISS-DF) lebih baik daripada proximal femur locking compression plate (PF-LCPs) untuk fraktur pertrokanterik. ${ }^{19}$

Aspek lain yang dinilai dari HHS ialah ada tidaknya deformitas dan range of motion (ROM). Pada penelitian ini tidak didapatkan adanya deformitas 6 pasien pasca operasi. Range of motion dari hip yang dinilai yaitu gerakan fleksi, abduksi, eksternal rotasi dan adduksi. Pada penelitian ini didapatkan 3 bulan pasca operasi fleksi hip $<70^{\circ}$, abduksi hip, eksternal rotasi hip dan adduksi hip $<10^{0}$, namun terjadi pening-katan derajat rentang gerak sendi setelah 6 bulan dan 12 bulan pasca operasi. Sebagian besar pasien mulai mencapai derajat gerakan sendi panggul normal saat 12 bulan pasca operasi.

$\mathrm{Li}$ et $\mathrm{al}^{16}$ meneliti indikasi, teknik operasi, dan keberhasilan operasi pada unstable fraktur subtrokanter dengan menggunakan reverse less invasive stable system-distal femur (LISS-DF) dimana sampel di follow up selama 28 bulan didapatkan rata-rata waktu recovery selama 4 bulan dan nilai harris hip score bervariasi dari $71-98$ poin. ${ }^{16}$

Giarso dan Dilogo 7 mengevaluasi penggunaaan reverse distal femoral locking plate pada fraktur subtrokanter dengan melihat skor fungsional pasien 0,6 , dan 12 bulan pasca operasi dan mendapatkan rerata HHS meningkat dari total skor 22 menjadi 75 , kemudian menjadi 86 setelah 12 bulan. $^{7}$

Pada penelitian ini didapatkan bahwa hasil akhir HHS 3 bulan pasca operasi ialah kategori poor dengan rerata skor 25,6. Pada HHS 6 bulan pasca operasi didapatkan 3 pasien kategori poor dan 3 pasien kategori fair dengan rerata skor 66,4. Pada HHS 12 bulan pasca operasi didapatkan 4 pasien kategori good dan 2 pasien kategori excellent dengan rerata skor 89,9.

\section{SIMPULAN}

Luaran fungsional pasien dengan neglected fraktur subtrokanter yang ditatalaksana menggunakan reversed distal femur limited contact-dynamic compression plate (reversed distal femur LC-DCP) di RS Bhayangkara Manado yang dinilai dengan HHS mendapatkan kategori poor untuk 3 bulan pasca operasi, kategori poor-fair untuk 6 bulan pasca operasi, dan kategori good-excellent untuk 12 bulan pasca operasi.

Perlu dilakukan penelitian lanjut menggunakan jumlah sampel yang lebih besar serta menilai tingkat kepuasaan pasien terhadap penggunaan reversed distal femur LC-DCP. 


\section{Konflik Kepentingan}

Penulis menyatakan tidak terdapat konflik kepentingan dalam studi ini.

\section{DAFTAR PUSTAKA}

1. Solomon L. Apley's System of Orthopaedics and Fractures (9th ed). Boca Raton: CRC press, 2013.

2. Bossart P. 83 - Hip and femur injuries [Internet]. Emergency Medicine (2nd ed). Elsevier Inc, 2020; p. 726-30. Available from: http://dx.doi.org/10.1016/B978-1-43773548-2.00083-5

3. Panteli M, Mauffrey C, Giannoudis P V. Subtrochanteric fractures: issues and challenges. Injury. 2017;48(10):2023-6.

4. Rahme DM, Harris IA. Intramedullary nailing versus fixed angle blade plating for subtrochanteric femoral fractures: a prospective randomised controlled trial. J Orthop Surg (Hong Kong). 2007; 15(3):278-81.

5. Edwards ER, Nork SE, Reilly MC. Fracture of the femur In: Skeletal Trauma (6th ed). Elsevier Inc. 2020; p. 1925-89. Available from: https://doi.org/10.1016/ B978-0-323-61114-5.00057-4

6. De Biase P, Biancalani E, Martinelli D, Cambiganu A, Bianco S, Buzzi R. Subtrochanteric fractures: two case reports of non-union treatment. Injury. 2018; 49(2018):S9-15. Available from: https:// doi.org/10.1016/j.injury.2018.11.038

7. Giarso P, Dilogo IH. Reverse distal femoral locking plate for subtrochanter femur fracture. Med J Indones. 2018;27(2):4652.

8. Tazawa R, Minehara H, Matsuura T, Kawamura T, Sakai R, Yoshida K, et al. Biomechanical evaluation of internal fixation for the treatment of comminuted subtrochanteric femur fractures. J Orthop Sci. 2020. Doi: https://doi.org/ 10.1016/j.jos.2020.03.002.

9. Nasional BPS dalam angka tahun 2012. Data Kecelakaan Lalu Lintas tahun 2013. 2013.

10. Zai PC, Wagiu A, Rawung R. Profil pasien trauma akibat kecelakaan lalu lintas yang dirawat di Instalasi Rawat Darurat Bedah RSUP Prof. Dr. R. D. Kandou Manado periode 1 Januari-31 Desember 2017. e-CliniC. 2018;6(2).

11. Jackson C, Tanios M, Ebraheim N. Management of subtrochanteric proximal femur fractures: a review of recent literature. Adv Orthop. 2018:1326701. Doi: 10. 1155/2018/1326701. Available from: https://doi.org/10.1155/2018/1326701

12. Huanguang Xie, Linzhen Xie, Jinwu Wang CC. Intramedullary versus extramedullary fixation for the treatment of subtrochanteric fracture: a systematic review and meta-analysis. Int $\mathbf{J}$ Surg. 2019;63:43-57.

13. Singh AK, Narsaria N, Gupta RK. A biomechanical study comparing proximal femur nail and proximal femur locking compression plate in fixation of reverse oblique proximal femur fractures. Injury. 2017;48(10):2050-3. Available from: http://dx.doi.org/10.1016/j.injury. 2017.05.029

14. Gogna P, Mukhopadhyay R, Singh A, Devgan A, Arora S, Batra A, et al. Contralateral reversed distal femoral locking plate for fixation of subtrochanteric femoral fractures. Chinese J Traumatol - English Ed. 2015;18(5):279-83. Available from: http://dx.doi.org/10.1016/j.cjtee.2015.1 1.002

15. Sri M, Wayan SI, Oka A, Gusti PI. Prosthesis pada fraktur kolum femur di RSUD Kabupaten Tabanan periode 2016-2017. E-Jurnal Medika Udayana. 2018;7(11): 1-7.

16. Li G, Li Z, Han N, Lu QY. A retrospective analysis of reversed femoral less invasive stable system (LISS) for treatment of subtrochanteric femoral fracture. Int $\mathbf{J}$ Surg. 2014;12(5):432-6. Available rom: http://dx.doi.org/10.1016/j.jisu. 2014.03. 006

17. Wang J, Ma JX, Lu B, Bai HH, Wang Y, Ma $\mathrm{XL}$. Comparative finite element analysis of three implants fixing stable and unstable subtrochanteric femoral fractures: proximal femoral nail antirotation (PFNA), proximal femoral locking plate (PFLP), and reverse less invasive stabilization system (LISS). Orthop Traumatol Surg Res. 2020;106(1):95101. Available from: https://doi.org/ 10.1016/j.otsr.2019.04.027

18. Han N, Sun GX, Li ZC, Li GF, Lu QY, Han $\mathrm{QH}$, et al. Comparison of proximal femoral nail antirotation blade and reverse less invasive stabilization system-distal femur systems in the treatment of proximal femoral fractures. 
Orthop Surg. 2011;3(1):7-13.

19. Lin SJ, Huang KC, Chuang PY, Lee CY, Huang TW, Lee MS, et al. The outcome of unstable proximal femoral fracture treated with reverse LISS plates. Injury. 2016;47(10):2161-8. 